\title{
Classificação do sistema de trilhas da unidade de conservação Parque Estadual Mata do Pau-Ferro, Areia, Paraíba, Brasil
}

\author{
Trail system classification of the conservation unit Pau-Ferro Forest State Park, \\ Areia, Paraíba, Brazil
}

\section{Clasificación del sistema de senderos de la unidad de conservación del Parque Estatal Forestal de Pau-Ferro, Areia, Paraíba, Brasil}

\author{
Valéria Raquel Porto de Lima \\ valeriaraquelportodelima@servidor.uepb.edu.br @ 0000-0001-7744-3502 \\ Universidade Estadual da Paraíba. Rua Baraúnas, 351 \\ Bairro Universitário - Campina Grande-PB. CEP 58429-500 Brasil \\ Jean Oliveira-Campos \\ jean.oliveira@academico.ufpb.br @ 0000-0002-2874-754X \\ Universidade Federal da Paraíba. Cidade Universitária \\ João Pessoa-PB. CEP 58051-900 Brasil
}

\section{INFO ARTÍCULO}

Recebido: 21-11-2021

Revisado: 13-12-2021

Aceito: 24-12-2021

\section{PALAVRAS-CHAVE:}

Mata Atlântica

Unidade de Conservação

Parque

Sistema de trilhas

\section{KEYWORDS:}

Atlantic Forest

Conservation Unit

Park

Track system

\begin{abstract}
RESUMO
A Unidade de Conservação (UC) Parque Estadual Mata do Pau-Ferro está localizada no município de Areia, estado da Paraíba, Nordeste do Brasil. A UC não possui um sistema de trilhas detalhado. Diante do exposto, o presente artigo elaborou um mapeamento das trilhas mais usadas pelos turistas que frequentam o Parque. Os procedimentos metodológicos consistiram no registro das coordenadas das trilhas usando um Sistema de Posicionamento Global - GPS e capturas fotográficas dos principais atrativos ao longo dos trajetos. Além disso, com o uso do software ArcGIS 10.2, as variáveis ambientais declividade, condições de terreno, cobertura vegetal e drenagem foram somadas para obter as classes de dificuldade das trilhas, usando como referências Silva (2016), Silva, Lima \& Panchaud (2016), e Silva \& Palhares (2020). Como resultado, foram mapeadas 4 trilhas, 2 integrações e 4 pontos principais que funcionam como atrativos turísticos. Em relação às classes de dificuldade das trilhas, $67,41 \%$ do sistema de trilhas foi classificado como "fácil", contexto que evidencia potencial para receber um público diverso de visitantes.
\end{abstract}

\begin{abstract}
The Mata do Pau-Ferro State Park Conservation Unit (UC) is located in the municipality of Areia, state of Paraíba, Northeastern Brazil. UC does not have a detailed trail system. In light of the above, this article drew up a mapping of the most used trails by tourists who frequent the Park. The methodological procedures consisted of recording the coordinates of the trails using a Global Positioning System - GPS and photographic captures of the main attractions along the paths. Also, using ArcGIS 10.2 software, the environmental variables slope, terrain conditions, vegetation cover and drainage were added to obtain the difficulty classes of the trails, using as references Silva (2016), Silva, Lima \& Panchaud (2016) and Silva \& Palhares (2020). As a result, 4 trails, 2 integrations and 4 main points that function as tourist attractions were mapped. Regarding the difficulty classes of the trails, $67.41 \%$ of the trail system was classified as "easy", a context that shows the potential to receive a diverse public of visitors.
\end{abstract}


PALABRAS CLAVE:

Bosque Atlántico

Unidad de Conservación

Parque

Sistema de senderos

\section{RESUMEN}

La Unidad de Conservación (UC) del Parque Estatal Forestal de Pau-Ferro está ubicada en el municipio de Areia, estado de Paraíba, noreste de Brasil. Esta no cuenta con un sistema de senderos detallado. Por lo tanto, asumiendo la ausencia de un mapa de identificación de senderos este trabajo realizó un mapeo de los senderos que son más utilizados por los turistas que frecuentan el Parque. Los procedimientos metodológicos consistieron en registrar las coordenadas de los senderos mediante un Sistema de Posicionamiento Global - GPS y captura fotográfica de los principales atractivos a lo largo de los senderos. Se utilizó el software ArcGIS 10.2 para evaluar las variables ambientales pendiente, condiciones del terreno, cobertura vegetal y drenaje que se agregaron para obtener los niveles de dificultad de los senderos, con base en las referencias de Silva (2016), Silva et al. (2016) y Silva \& Palhares (2020). Como resultado, se mapearon 4 senderos, 2 integraciones y 4 puntos principales que funcionan como atractivos turísticos. En cuanto a las clases de dificultad de los senderos, el $67,41 \%$ del sistema de senderos se clasificó como "fácil", contexto que muestra el potencial para recibir un público diverso de visitantes.

\section{INTRODUÇÃO}

A implantação de unidades de conservação para resguardar a biodiversidade constitui a principal reação do homem frente à degradação dos ecossistemas no Brasil e no mundo (Myers et al., 2000; Primack \& Rodrigues, 2001; Aguiar et al., 2013). O principal instrumento jurídico de criação das Unidades de Conservação no Brasil é a Lei 9.985, de 2000, que instituiu o Sistema Nacional de Unidades de Conservação (SNUC), do qual estabelece parâmetros e categorias de manejo com diferentes graus de proteção, dividindo as áreas em Unidades de Proteção Integral e Unidades de Uso Sustentável.

A categoria Parque encontra-se no grupo das unidades de Proteção Integral, cujo objetivo básico é preservar a natureza, sendo permitido apenas o uso indireto de seus recursos naturais, atividades educacionais, científicas e recreativas. Segundo descrição realizada por Diaz del Olmo e Molina Vázquez (1985), para os parques nacionais da Andalucia, os Parques brasileiros seguem os mesmos princípios.

O contexto de criação de Unidades de Conservação (UCS) no Brasil é permeado por conflitos que materializam o interesse de diversos agentes envolvidos, como representantes do setor público e privado. Desse modo, a gestão de Unidades de Conservação é um desafio, principalmente no tocante ao controle das atividades que se desenvolvem dentro e nas áreas próximas as UCs, e são detentoras de potencial para perturbar os ecossistemas protegidos.

No estado da Paraíba, entre as unidades conservação da Mata Atlântica, o Parque Estadual Mata do Pau-Ferro, no município de Areia, abriga um dos maiores fragmentos, sendo um dos mais representativos da região Nordeste (Tabarelli \& Santos, 2004). Trata-se de um fragmento de Floresta Estacional Semidecidual Montana (Floresta Ombrófila), situado na vertente leste do planalto da Borborema, em condição de refúgio ou brejo de altitude (Veloso et al., 1991; Ab'Saber, 2003; Tabarelli \& Santos, 2004; Bétard et al., 2007; Medeiros \& Cestaro, 2019).

Em função das características ambientais, o Parque Estadual Mata do Pau-Ferro é um importante atrativo turístico da microrregião do Brejo Paraibano, além de fornecer proteção aos ecossistemas remanescentes (Marques et al., 2019; Santos et al., 2020). Embora tenha tamanha importância, a UC ainda não possui um detalhado do sistema de trilhas, conforme é atestado em seu Plano de Manejo, o que desfavorece a divulgação da área, bem como o cumprimento dos objetivos que levaram a sua criação (Santos et al., 2020). Tal aspecto se deve em parte à escassez de recursos para gestão e manutenção das estruturas físicas da área protegida.

O Plano de Manejo da UC não apresenta o mapeamento das trilhas, tampouco a extensão das mesmas, demonstrando que a atividade de visitação ocorre em condições informais, isto é, sem a infraestrutura e orientações necessárias. Essa conjuntura inviabiliza mensurar e estimar os impactos da referida atividade na unidade, posto que não se sabe ao certo onde ocorre.

Por tratar-se de um importante ponto turístico do Brejo Paraibano, a elaboração de tal produto pronunciará, de forma mais assertiva o potencial turístico, e suscitará a realização de pesquisas e práticas 
de educação ambiental, pontos, estes, que se encontram entre os objetivos perseguidos pela categoria Parque. Mediante o exposto, o presente artigo se propõe a mapear as trilhas do Parque Estadual Mata do Pau-Ferro e as classes de dificuldade delas, com vistas a fornecer contribuições no que diz respeito ao levantamento das potencialidades turísticas e divulgação da importância da área para proteção da biodiversidade.

\section{REFERENCIAL TEÓRICO}

A criação de áreas protegidas a partir do século XX, teve como um dos principais objetivos resguardar a biodiversidade, sendo esse um mecanismo para que as sociedades reajam aos cenários de degradação ambiental (Dorst, 1973; Primack \& Rodrigues, 2001; Juras, 2010). O marco moderno do estabelecimento de áreas protegidas, foi a criação do Parque Nacional de Yellowstone, nos Estados Unidos, em março de 1872. A partir do feito, o conceito de proteção da natureza progressivamente espalhou-se por todo o mundo, e, no Brasil, o início da política de áreas protegidas teve início em 1937, com a criação do Parque Nacional de Itatiaia (Brasil, 2007; Godoy \& Leuzinger, 2015).

Na mesma década também foram criadas duas áreas de proteção, a saber, o Parque Nacional do Iguaçu e o Parque Nacional Serra dos Órgãos, ambos no ano de 1939. Assim, tal contexto coloca o Brasil entre os países que mais tardaram no estabelecimento de políticas de áreas protegidas (Morsello, 2001; Medeiros, 2006).

Nas décadas seguintes instrumentos legais possibilitaram a criação de novas tipologias de áreas protegias. Entre eles, a Lei 4.771, de 15 de setembro de 1965, conhecida como Código Florestal, a Lei n 5.197, de 3 de janeiro de 1967, conhecida como Código de Fauna, a Lei no 6.513, de 20 de dezembro de 1977, a Lei $n^{\circ}$ 6.902, de 27 de abril de 1981, o Decreto $n^{\circ}$ 89.336, de 31 de janeiro de 1984, a criação do Instituto Brasileiro de Meio Ambiente e dos Recursos Naturais Renováveis, em 1989 e o Decreto n 98.897, de 30 de janeiro de 1990 (Brasil, 2007; Pureza et al., 2015).

Em vista dos avanços, o país finda a década de 1990 com uma variedade de categorias de áreas protegidas, a exemplo dos parques nacionais, florestas nacionais, estações ecológicas, áreas de proteção ambiental, reservas ecológicas, áreas de relevante interesse ecológico e reservas particulares do patrimônio natural (Morsello, 2001; Drummond et al., 2010).

Apenas no século XXI, o país consegue a criação de um sistema para gestão das áreas protegidas, o Sistema Nacional de Unidades de Conservação da Natureza - SNUC, instituído pela Lei n 9.985, de 18 de julho de 2000, que passa a estabelecer os critérios e as normas para a criação, implantação e gestão de unidades de conservação, estabelecendo um novo panorama acerca das áreas protegidas no país (Brasil, 2007, 2011). Mesmo com o expressivo avanço, se comparado a outros períodos em que não existiam estratégias ou políticas de conservação e preservação da natureza no Brasil, os desafios para manter as UC já criadas nas esferas federal, estadual e municipal são inúmeros, sobretudo na atual conjuntura política vivenciada no Brasil.

Para Castro Júnior, Coutinho e Freitas (2009) a lei é o resultado do trabalho de mais de duas décadas de trabalho, visto que a primeira proposta foi realizada ainda em 1979, e só em 1992 uma versão foi enviada ao Congresso Nacional, onde tramitou por oito anos, suscitando debates. Os debates abrangiam ambientalistas, proprietários de terra, populações tradicionais e setores produtivos com interesse no manejo dos recursos naturais, dessa forma, mesmo antes de sua promulgação, o SNUC gerou variados conflitos entre as partes interessadas.

O SNUC é composto por dois grupos de Unidades de Conservação, Unidades de Proteção Integral e Unidades de Uso Sustentável. O grupo de Proteção Integral tem por objetivo preservar a natureza, mantendo os ecossistemas livres das perturbações antrópicas, admitindo apenas o uso indireto dos recursos naturais, tendo a categoria Parque de domínio nacional, estadual e municipal como a mais representativa (Brasil, 2020). Os parques visam a preservação dos ecossistemas naturais e beleza cênica, permitindo a realização de atividades, como pesquisa científica, educação ambiental, recreação e turismo ecológico (Brasil, 2011). 
Ressalta-se, no entanto, que a realização de pesquisas bem como a visitação pública estão sujeitas a normas e restrições estabelecidas pelo órgão gestor e pelo Plano de Manejo da unidade.

O Plano de Manejo trata-se de um documento de caráter multidisciplinar, que inclui estudos do meio biótico, abiótico e social (Diegues, 2008; Brasil, 2011). Suas características são variáveis, e no conjunto visam orientar as atividades desenvolvidas no território da Unidade de Conservação. Em sua estrutura, o plano também aponta os procedimentos para implantação de estruturas físicas na unidade de conservação, com vistas para a melhoria no quadro de gestão (Ibama, 2002; Souza, Vieira \& Silva, 2015).

Nesse sentido, se mostra um dos principais recursos de orientação para a atividade de turística, especialmente no diz respeito a capacidade das trilhas, estruturas, intervalos de tempo e normas de conduta. A visitação em parques nacionais é essencial para o arrecadamento de recursos financeiros, que, por sua vez, podem ser empregados na gestão dessas áreas. A prática propicia ao turista a oportunidade de conhecer, entender e valorizar a biodiversidade (Canto-Silva \& Silva, 2017; Gomes \& Cunha, 2018). Para tanto, se faz necessário a instalação de uma infraestrutura básica para atender os turistas e conduzi-los durante a passagem pela Unidade de Conservação - contexto em que as trilhas se mostram imprescindíveis, em função das possibilidades oferecidas, como a interpretação ambiental e contato dos visitantes com o ambiente protegido (Robim \& Tabanez, 1993; Rezende \& Cunha, 2014; Costa et al., 2019).

Em face do papel desempenhando pelas trilhas nas Unidades Conservação, se torna fundamental oferecer aos visitantes informações básicas a respeito do leito das trilhas, como orientações de conduta, sinalização, mapas de trajetos, pontos de referência, distâncias e medidas a serem adotadas, em casos de acidentes e graus de dificuldade, considerando as características ambientais e o esforço físico a ser dispensado na realização (Silva et al., 2016; Silva \& Palhares, 2020).

Sendo um dos principais atrativos das áreas protegidas, e também responsável pelo deslocamento entre pontos da paisagem, as trilhas necessitam de um preciso monitoramento ambiental, haja vista que provocam alterações no sistema ambiental (Figueiró \& Coelho Netto, 2009; Boquimpani-Freitas et al., 2020). Além do que, a falta de planejamento pode levar as trilhas a receberem números de visitantes que ultrapassam o recomendando para as características ambientais apresentadas, ocasionando pressões superiores à capacidade de suporte, causando consequências danosas à biodiversidade (Primack \& Rodrigues, 2001; Rangel et al., 2013).

Nesse contexto, Sistemas de Informações Geográficas - SIGs, ao permitirem a integração de dados ambientais e a representação espacial de fenômenos, podem ser utilizados para fins de gestão, especialmente visando o mapeamento das trilhas, seus atrativos, e obstáculos (Decanini, 2001; Silva et al., 2016). O mapeamento, por sua vez, possibilita o planejamento da capacidade de suporte das trilhas e antecipação de possíveis impactos causados pela visitação, considerando a distribuição das trilhas e dos ecossistemas da área protegida.

O uso de SIGs torna-se oportuno em um contexto onde as Unidades de Conservação apresentam escassez de pessoal para atividades de campo (Drummond et al., 2010; Godoy \& Leuzinger, 2015), pois, apesar da relevância das unidades de conservação para o país, são enfrentadas inúmeras dificuldades. Dentre elas, encontram-se a escassez de recursos financeiros e falta de pessoal qualificado para manejo, fiscalização e gerenciamento (Brasil, 2007; Simões, 2008).

Parte das dificuldades que assolam a gestão das áreas protegidas no país, é resultado da falta reconhecimento da importância das mesmas para a manutenção da biodiversidade. Frente a isso, faz-se necessária uma maior atuação do Poder Público na resolução dos conflitos que se instalam, bem como na conscientização da população acerca da importância dessas áreas para conservação da biodiversidade, oferta de serviços ecossistêmicos, e também para o desenvolvimento social, econômico e cultural, alicerçado nas bases da sustentabilidade (Ganem \& Drummond, 2010; Medeiros et al., 2011). 


\section{METODOLOGIA}

O município de Areia está localizado no estado da Paraíba, assentado na borda úmida do Planalto da Borborema em condição de Brejo de Altitude, área de exceção que apresentam maior umidade em relação ao espaço onde está inserida - característica que favorece a manutenção da formação florestal da Mata Atlântica, sendo, portanto, considerado como uma área de refúgio florestal (Andrade \& Lins, 1964; Ab'Sáber, 2003; Medeiros \& Cestaro, 2019) em meio a uma condição de semiaridez, caracterizada pela vegetação de Caatinga, uma formação florestal tropical seca (Pennington et al., 2004), que ocupa 9\% do território brasileiro.

O Parque Estadual Mata do Pau-Ferro está localizado na zona rural do município, apresentando uma área de 607,96 hectares, onde abriga um fragmento florestal, o qual constitui um dos mais extensos remanescentes de Mata Atlântica do estado (Tabarelli \& Santos, 2004) (mapa 1). A área protegida foi criada em 19 de outubro de 1992, como Reserva Ecológica e recategorizada para a categoria parque de domínio estadual, através do Decreto Estadual n 26.098, de 04 de agosto de 2005, passando a constituir o Parque Estadual Mata do Pau-Ferro (Decreto no 26.098, de 04 de agosto de 2005, 2005).

O território municipal está inserido nos domínios da bacia hidrográfica do rio Mamanguape, apresentando rios intermitentes, com padrão de drenagem dendrítico (Campos \& Lima, 2020). O relevo é predominantemente forte ondulado, com solos profundos e mediamente férteis, estando a sede municipal situada a aproximadamente 620 metros de altitude (Beltrão et al., 2005), enquanto a vegetação é composta predominantemente por fisionomias da Mata Atlântica, ocorrendo também porções de Caatinga nas extremidades a noroeste do município. Segundo a classificação climática de Köppen, o clima municipal é do tipo As, quente e úmido com chuvas de outono e inverno (Paraíba, 1985).

Os levantamentos florísticos mostram que a Unidade de Conservação comporta pelo menos quatro espécies vulneráveis ou ameaçadas de extinção, pau-d'arco-roxo (Handroanthus impetiginosus (Mart. ex DC.) Mattos), sucupira (Bowdichia virgilioides Kunth), cedro (Cedrela fissilis Vell.) e pau-ferro (Erythroxylum pauferrense Plowman), sendo esta última endêmica do Brejo de Altitude onde se encontra o Parque (SFB, 2019; H. A. Santos et al., 2020). Esse arranjo evidencia a necessidade de esforços para proteção dos ecossistemas do Parque e de suas áreas vizinhas.

Observado o exposto, para o desenvolvimento do trabalho na Unidade de Conservação foram utilizados os seguintes materiais: imagem de radar com Modelo Digital de Terreno - MDE com resolução de 12,5 m ALOS/PALSAR; imagem do satélite Sentinel-2, sensor MSI, datada de novembro de 2019 (período com menor cobertura de nuvens na área de estudo) adquirida gratuitamente na plataforma Sentinel Hub; base cartográfica do Brasil, Nordeste, Paraíba e do município de Areia no formato shapefile; polígono no formato shapefile da Unidade de Conservação disponibilizado pela SUDEMA; aparelho de GPS portátil modelo Etrex Garmin Vista; aplicativo Android GPS Essentials versão 4.4.27; câmera fotográfica; e softwares ArcGIS versão $10.2^{\circledR}$ e Excel.

Os trabalhos de campos ocorreram nos dias 10, 11 e 29 de agosto de 2019 e 10 março de 2020. Com o auxílio de um guia turístico local, foram percorridas todas as trilhas e realizado registro fotográfico dos principais atrativos ao longo dos trajetos. Todas as trilhas, assim como todos os atrativos foram gravados no GPS portátil e também no GPS Essentials de forma automática. A visita de março foi realizada no intuito de verificar atualizações sofridas pelas trilhas.

Os dados do GPS foram manipulados no software ArcGIS para elaboração do mapa de trilhas, enquanto as trilhas do aplicativo foram utilizadas para validação das mesmas. Posteriormente, os percursos das trilhas foram sobrepostos com mapas de altitude e declividade gerados a partir do MDE, e, posteriormente, feita a extração das informações que foram utilizadas para elaboração de gráficos.

Para mapear as classes de dificuldades apresentadas pelas trilhas, foi utilizada a metodologia adaptada por Silva (2016), Silva, Lima e Panchaud (2016), e Silva e Palhares (2020), que está baseada na atribuição de notas, sobreposição e somatório das variáveis ambientais declividade, cobertura vegetal, condições de terreno e drenagem da água, com uso de geoprocessamento, de modo a verificar os graus de dificuldade das trilhas. 
Para tanto, com uso do ArcGIS, as variáveis declividade, cobertura vegetal, condições de terreno e drenagem da água foram divididas em classes, posteriormente receberam notas de 1 a 4 e foram reclassificadas em muito fácil, fácil, moderada e difícil - conforme as dificuldades que oferecem para realização das trilhas (tabela 1). A declividade e drenagem foram obtidas a partir do processamento do MDE no software ArcGIS, esta última foi gerada a partir das curvas de nível do terreno. As áreas mais baixas do terreno onde se encontram os cursos de água receberam a maior nota, dado que o escoamento é lento e pode afetar a realização das trilhas, enquanto as áreas mais altas do modelado local, onde a drenagem se apresenta rápida e livre, receberam a menor nota.

As informações da cobertura vegetal foram obtidas a partir da classificação supervisionada de uma imagem de satélite do Sentinel - 2, no software ArcGIS, com uso do classificador Maximum Likelihood, onde foram encontradas as seguintes classes: vegetação alta, vegetação média e vegetação baixa. As condições do terreno, por sua vez, foram obtidas a partir da cobertura vegetal, tendo em vista que os obstáculos encontrados na superfície das trilhas referem-se, na área de estudo, às árvores caídas, sendo estas mais frequentes nas áreas de vegetação alta.

Todas as variáveis ambientais foram geradas no formato raster, e após a atribuição das notas, foi realizado o somatório das mesmas com o uso do ArcGIS. Posteriormente, o produto obtido do somatório foi reclassificado com base nas notas finais e convertido para o formato shapefile (tabela 2).

Por fim, o arquivo shapefile, com as classes de dificuldade, foi utilizado para recortar as trilhas mapeadas, permitindo verificar as classes de dificuldade encontradas nas mesmas e os percentuais de distância que ocupam no sistema de trilhas da área protegida.

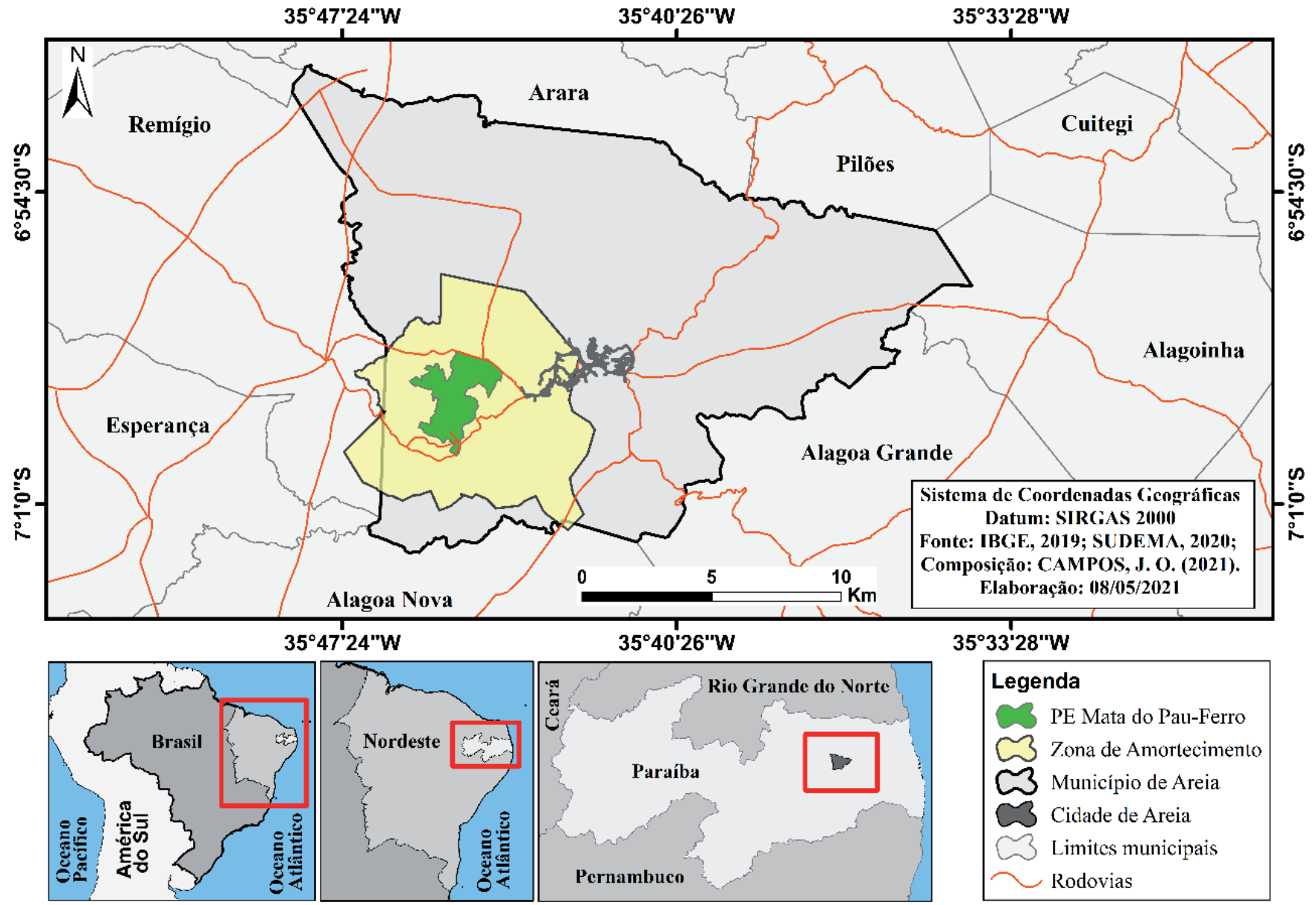

Mapa 1. Localização do Parque Estadual Mata do Pau-Ferro no município de Areia - PB.

Fonte: Elaboração própria. 
Tabela 1. Variáveis ambientais, notas e reclassificações atribuídas

\begin{tabular}{|c|c|}
\hline VARIÁVEIS AMBIENTAIS & NOTAS E RECLASSIFICAÇÕES \\
\hline Declividade & $\begin{array}{l}\text { A inclinação do terreno foi dividida nos seguintes intervalos: relevo suave }(0-10 \%) \text {, relevo } \\
\text { ondulado (10-20\%), relevo forte-ondulado ( } 20-30 \%) \text { e relevo montanhoso (>30\%). Os } \\
\text { intervalos, por sua vez, receberam as seguintes notas e reclassificações: } 2 \text { - fácil, } 3 \text { - } \\
\text { moderado, } 4 \text { - difícil e, } 5 \text { - muito difícil. }\end{array}$ \\
\hline $\begin{array}{l}\text { Condições } \\
\text { do terreno }\end{array}$ & $\begin{array}{l}\text { As condições do terreno referem-se aos obstáculos encontrados. Em função disso, adotou- } \\
\text { se as condições: superfície lisa, superfície com poucos obstáculos, superfície com muitos } \\
\text { obstáculos e superfície muito irregular/trechos de ascensão. As mesmas receberam as } \\
\text { seguintes notas e reclassificações: } 2 \text { - fácil, } 3 \text { - moderado, } 4 \text { - difícil e, } 5 \text { - muito difícil. }\end{array}$ \\
\hline $\begin{array}{l}\text { Cobertura } \\
\text { vegetal }\end{array}$ & $\begin{array}{l}\text { Neste critério adotou-se classes generalizadas de cobertura vegetal, expressas em } \\
\text { vegetação alta, vegetação média, vegetação baixa e trecho sem vegetação. As classes } \\
\text { receberam as seguintes notas e reclassificações: } 1 \text { - muito fácil, } 2 \text { - fácil, } 3 \text { - moderado e, } \\
4 \text { - difícil. }\end{array}$ \\
\hline Drenagem & $\begin{array}{l}\text { A drenagem está relacionada à presença de água nas trilhas, por isso foram adotadas as } \\
\text { classificações: drenagem natural rápida e drenagem natural lenta ou impedida, as mesmas } \\
\text { receberam as seguintes notas e reclassificações: } 2 \text { - fácil e } 3 \text { - moderado. }\end{array}$ \\
\hline
\end{tabular}

Fonte: Adaptado de Silva (2016) e Silva et al. (2016).

Tabela 2. Intervalos utilizados para classificação dos graus de dificuldade

\begin{tabular}{|c|l|}
\hline INTERVALOS & \multicolumn{1}{|c|}{ CLASSES DE DIFICULDADE } \\
\hline Entre 7 e 9 & Muito fácil \\
\hline$>9$ a 11 & Fácil \\
\hline$>11$ a 13 & Moderada \\
\hline$>13$ a 15 & Difícil \\
\hline$>15$ a 17 & Muito difícil \\
\hline
\end{tabular}

Fonte: Adaptado de Silva (2016) e Silva et al. (2016).

\section{RESULTADOS E DISCUSSÕES}

A estrutura verificada ao longo do trabalho realizado na Unidade de Conservação, indica a existência de diversos conflitos: a falta de fiscalização, isto é, o não reconhecimento dos limites da área por parte de moradores locais, abertura de trilhas não planejadas, e a manutenção da agropecuária em pontos específicos da área protegida. Esses conflitos, por sua vez, podem enfraquecer a visitação, tendo em vista a dificuldade de controle dos órgãos gestores sobre quem acessa os espaços protegidos (Figueiró \& Coelho Netto, 2009; Costa et al., 2019; Pereira et al., 2019; Silva \& Palhares, 2020). A supressão dos conflitos, por outro lado, pode evidenciar as particularidades ambientais e favorecer a visitação.

No total foram mapeadas 4 trilhas, 2 integrações que conectam as trilhas e 4 pontos principais da paisagem que funcionam como atrativo turístico (mapa 2). As trilhas mapeadas foram Trilha Inicial, Trilha do Cumbe, Trilha das Flores e Trilha da Barragem, enquanto as integrações mapeadas recebem o nome de Integração 1 e Integração 2. Os pontos atrativos, portanto, são Munguba, Cachoeira, Barragem e Casarão. A nomenclatura das trilhas e dos atrativos foram atribuídos pelas comunidades tradicionais que estão assentadas no entorno da UC. 
Durante a visitação, os turistas selecionam as trilhas através da quilometragem ou de um atrativo, como a Barragem. Em função disso, as integrações, possibilitam percursos alternativos no intuito de aumentar as distâncias. Como aqui são apresentadas apenas as extensões das trilhas, para mensurar a extensão total percorrida pelo visitante é necessário realizar a soma das distâncias percorridas, considerando o ponto de início, a trilha selecionada e o percurso de volta.

A maior parte dos visitantes enquadra-se como estudantes da Educação Básica, professores, turistas experientes, moradores locais, pesquisadores e moradores locais (Pereira et al., 2019; Campos \& Lima, 2020; Santos et al., 2020). E conforme o Plano de Manejo, os grupos de visitantes não devem ultrapassar 50 pessoas e devem estar acompanhados por guias autorizados, além disso é necessário um intervalo de 30 minutos entre cada um deles (Santos et al., 2020).

Ao longo das trilhas, na maior parte do tempo o campo de visão dos visitantes é limitado pelos caules e copas das árvores, sendo comum o avistamento de aves e mamíferos. O solo, por sua vez, aparece sem cobertura vegetal na maior parte do trajeto, sendo também verificados trechos com cobertura orgânica, como plântulas, folhas, galhos, frutos e dejetos de animais que habitam a área. Ocorrem também trechos a céu aberto, onde o campo de visão é ampliado, esses, no entanto, estão situados nas clareiras localizadas na porção central do Parque, bem como na porção sul, onde a vegetação possui menor porte. No período chuvoso da região, que ocorre entre fevereiro e julho, a execução das trilhas torna-se dificultosa em função da presença de água nas trilhas e da superfície do solo que se torna escorregadia, aumentando o risco de acidentes.

A Trilha Inicial é o percurso que possui menor extensão, funciona como o início de todas as trilhas, uma vez que é compartilhada, com início no Centro de Turismo Jonas Camelo de Souza, que está localizado na entrada do Parque (mapa 2 e figura 1). No centro é possível realizar agendamentos para a realização de trilhas guiadas, bem como conhecer sobre a duração das mesmas e os atrativos turísticos encontrados no percurso. Os guias locais residem na própria comunidade e recebem formação para a condução de visitantes na Unidade de Conservação.

A Trilha do Cumbe é a segunda menor trilha, apresentando extensão de 0,168 km, ao mesmo tempo, em que possui a menor variação de declividade e altitude (figura 2). Geralmente é escolhida por visitantes que procuram caminhadas rápidas e públicos de excursões escolares, além de tratar-se de uma das primeiras trilhas abertas e controladas da Unidade de Conservação, sendo a única que apresenta uma placa com indicação do nome e orientações aos visitantes. A chegada na trilha se dá através da Integração 1 ou do percurso inicial da Trilha das Flores, conforme o mapa 2.

Na margem desta trilha recebe destaque a munguba (figura 3), indivíduo de Eriotheca macrophylla (K.Schum.) A.Robyns, espécie vegetal nativa da Mata Atlântica (Santos et al., 2020), considerado um dos pontos de parada da trilhada, principalmente para registro fotográfico, em vista que indivíduos desse porte são escassos em decorrência do desmatamento nas áreas adjacentes da unidade.

Assim, a trilha das Flores, inicialmente, é direcionada para o leste e posteriormente projeta-se para o sul após decorridos mil metros, onde se conecta com a Trilha da Barragem. A altitude da trilha varia entre 520 e 640 metros, ao passo que a declividade se distribui entre 0 e 50\%, o que demonstra a existência de declives significativos no percurso de 2,452 km (figura 4). Essa trilha encontra-se situada em uma das áreas onde a vegetação se apresenta de forma mais densa na Unidade de Conservação, por isso é escolhida por pesquisadores para a realização de estudos sobre a biodiversidade (Santos et al., 2020).

Por fim, a Trilha da Barragem é maior entre as trilhas da Unidade de Conservação, possui 4,580 km de extensão, tendo início na parte norte e encerrando na porção sul do Parque (mapa 2). Ao mesmo tempo, pode ser iniciada ao sul e finalizada ao norte no Centro de Turismo. Esta, apresenta a maior variação de altitude dentre as trilhas (480 a $620 \mathrm{~m}$ ), porém menor variação na declividade, quando comparada a Trilha das Flores (figura 5). A declividade é um fator importante na sustentabilidade das trilhas, estando diretamente associada com a vulnerabilidade a erosão. Portanto, os percursos podem ser avaliadas do ponto de vista da declividade, com vistas a priorizar trilhas onde se verificam os menores percentuais para grupos maiores de visitantes (Marion \& Wimpey, 2017). 


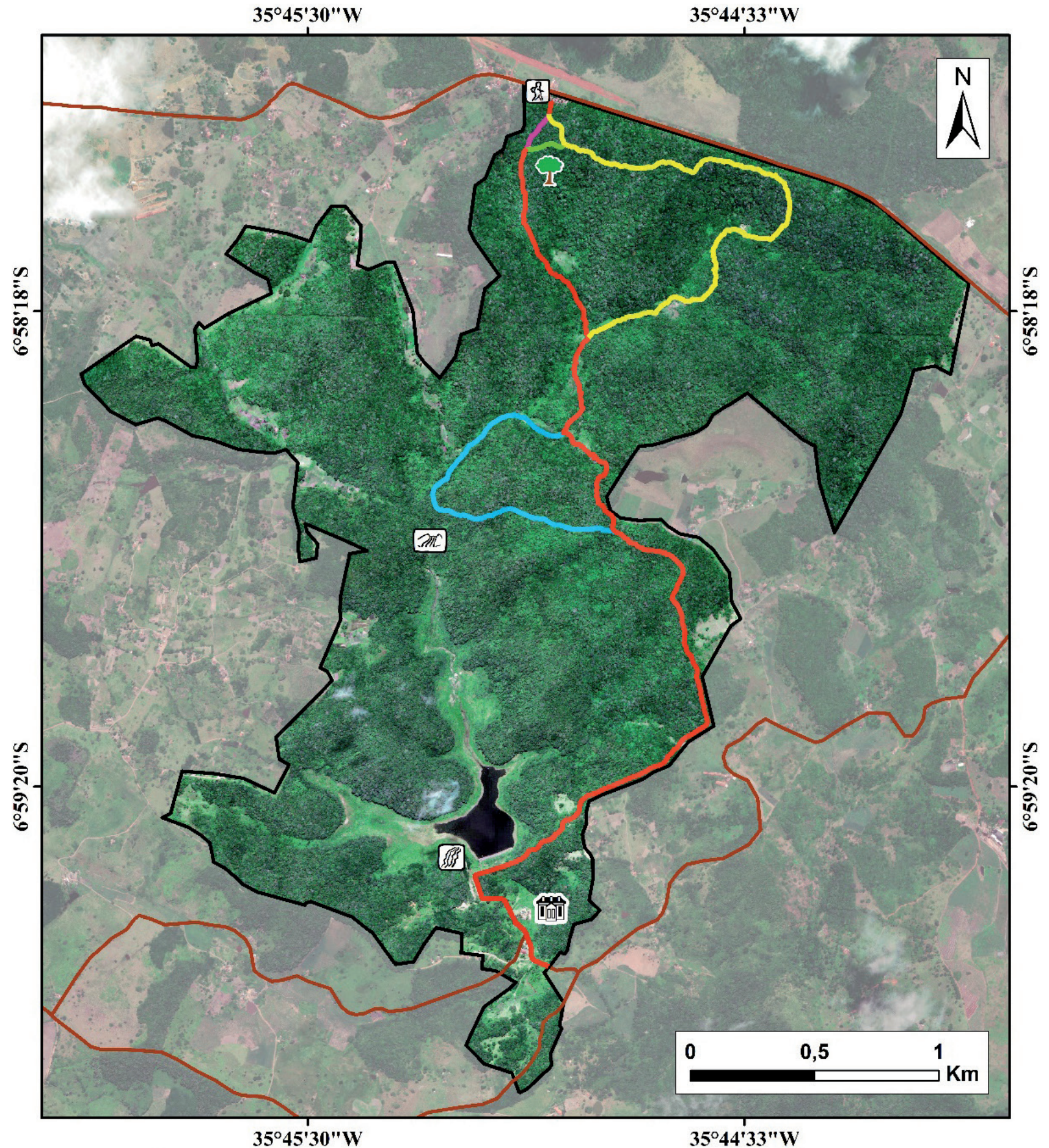

\begin{tabular}{|l|c|}
\hline \multicolumn{1}{|c|}{ Trilha } & Comprimento $(\mathbf{k m})$ \\
\hline Trilha Inicial & $\mathbf{0 , 0 5 2}$ \\
\hline Trilha do Cumbe & $\mathbf{0 , 1 6 8}$ \\
\hline Integração 1 & $\mathbf{0 , 1 7 2}$ \\
\hline Integração 2 (Bifurcação) & 1,544 \\
\hline Trilha das Flores & $\mathbf{2 , 4 5 2}$ \\
\hline Trilha da Barragem & $\mathbf{4 , 5 8 0}$ \\
\hline
\end{tabular}

\begin{tabular}{|c|c|}
\hline 87 & Centro de Turismo \\
\hline & Munguba \\
\hline $\mathrm{OMC}$ & Cachoeira \\
\hline 埩 & Barragem \\
\hline 可䅇 & Casarão \\
\hline
\end{tabular}

\begin{tabular}{|} 
Início das Trilhas \\
Integração 1 \\
Trilha do Cumbe \\
Integração 2 (Bifurcação) \\
Trilhas das Flores \\
Trilha da Barragem \\
Rodovias \\
PE Mata do Pau-Ferro
\end{tabular}

Mapa 2. Trilhas do Parque Estadual Mata do Pau-Ferro. Fonte: Elaboração própria. 


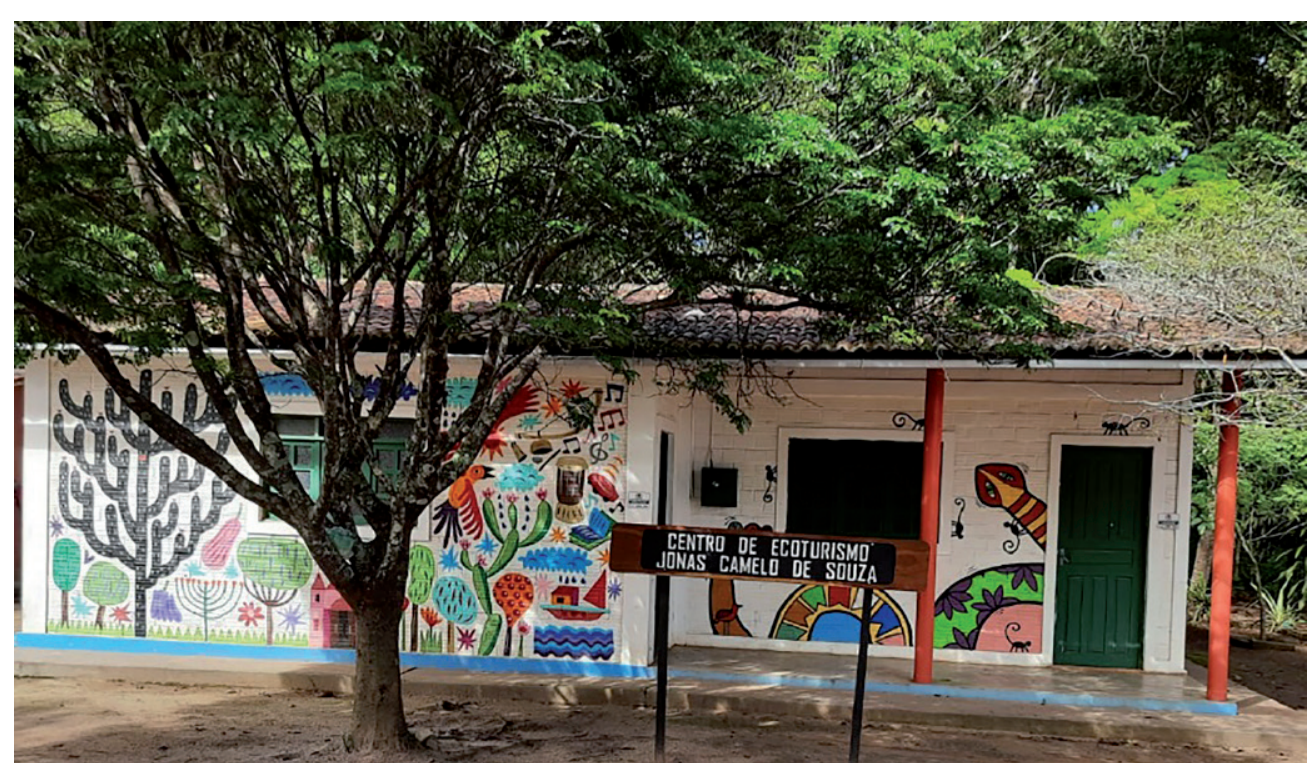

Figura 1. Centro de Turismo Jonas Camelo de Souza. Fonte: Elaboração própria.

(A) Hipsometria - Trilha do Cumbe

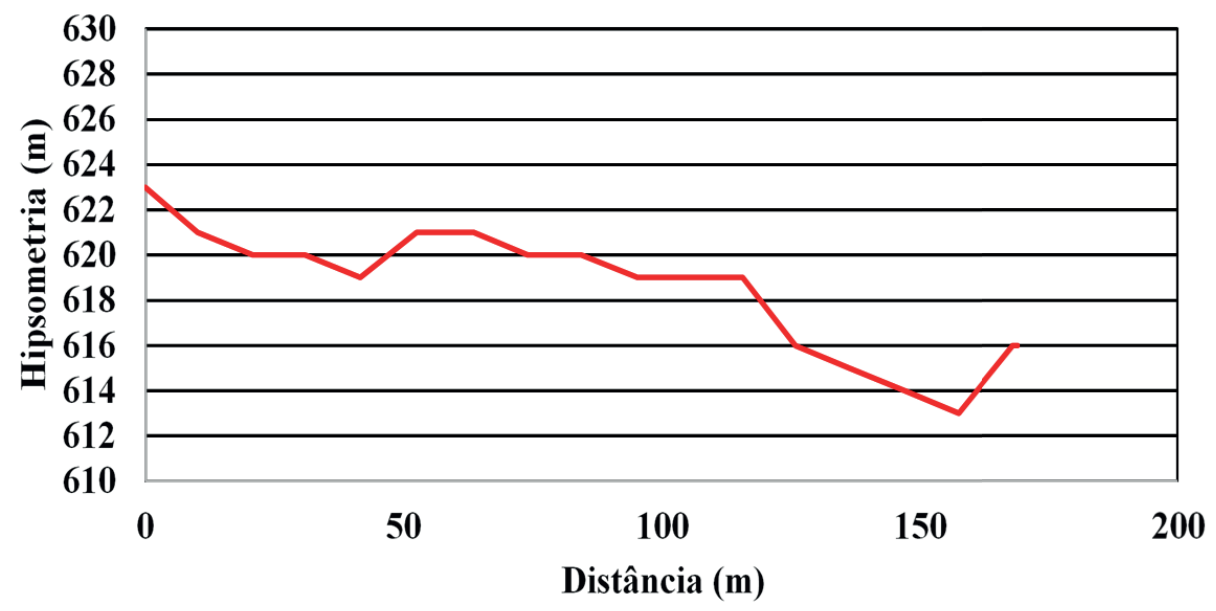

(B) Declividade - Trilha do Cumbe

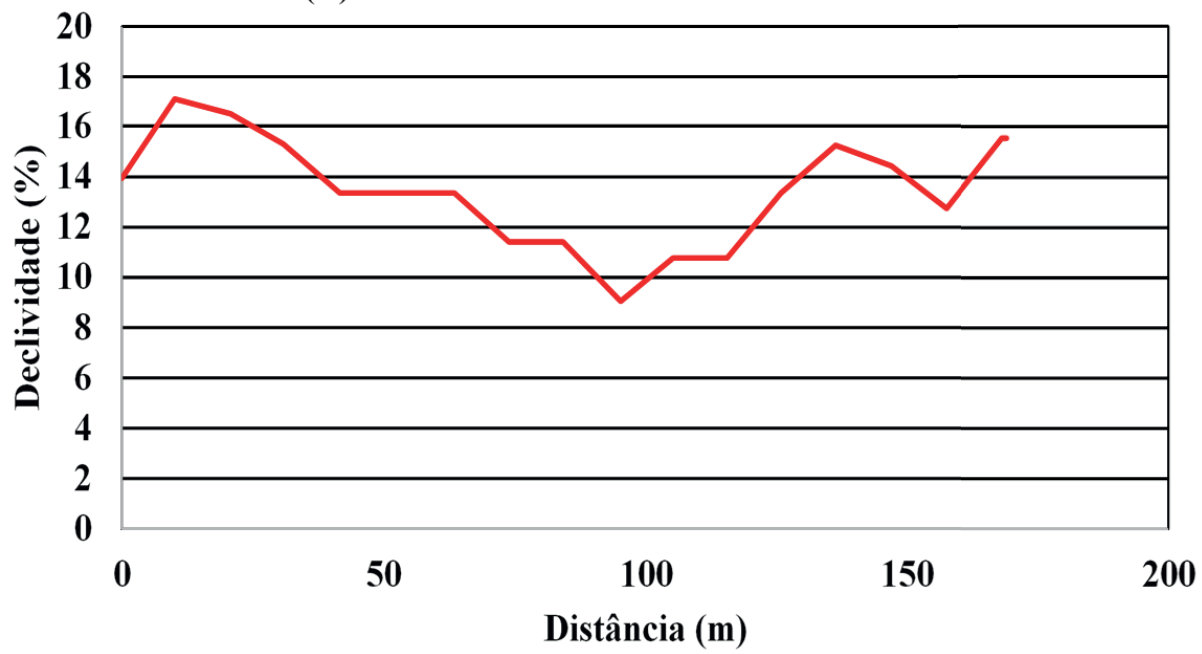

Figura 2. Hipsometria e declividade da Trilha do Cumbe. Fonte: Elaboração própria. 


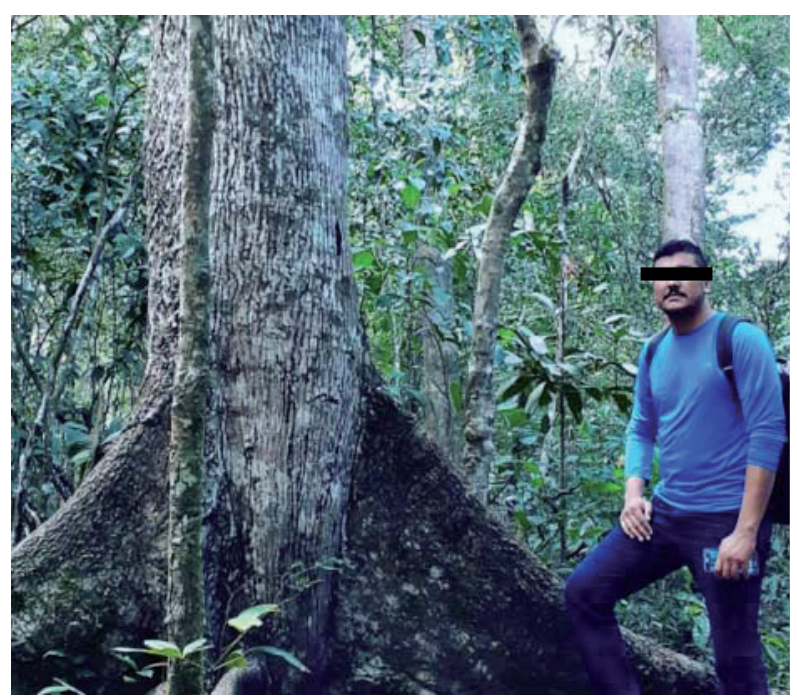

Figura 3. Munguba na margem da Trilha do Cumbe. Fonte: Elaboração própria.

(A) Hipsometria - Trilha das Flores

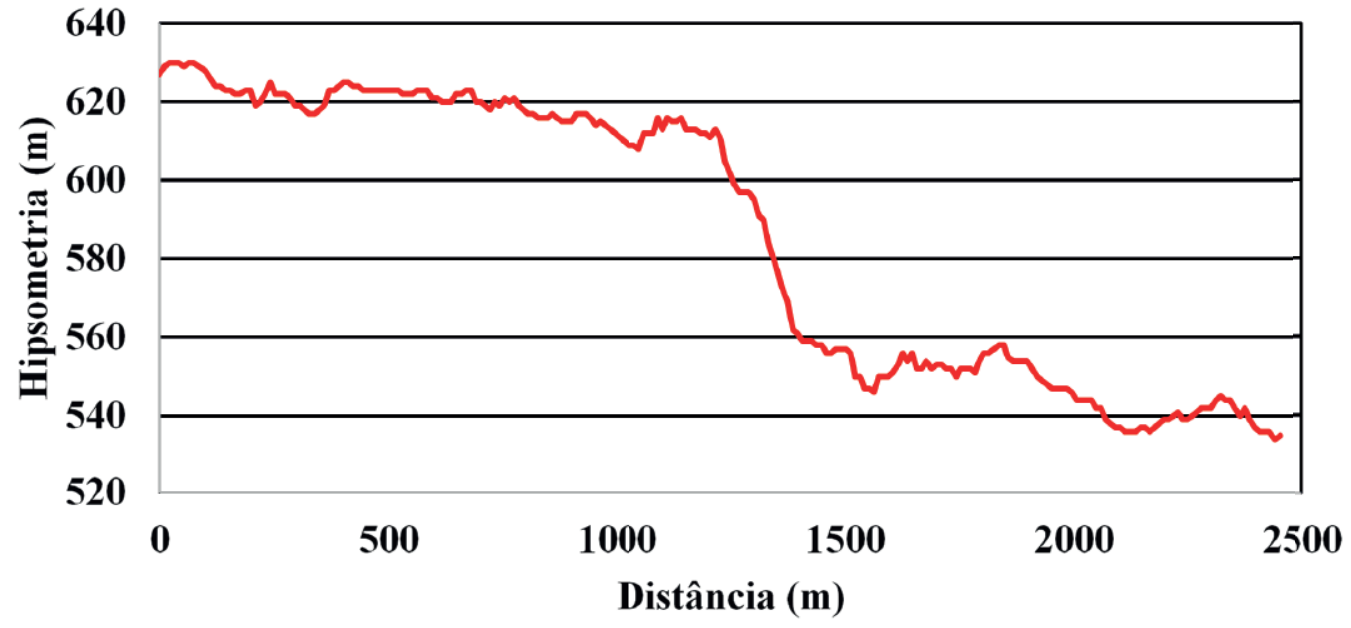

(B) Declividade - Trilha das Flores

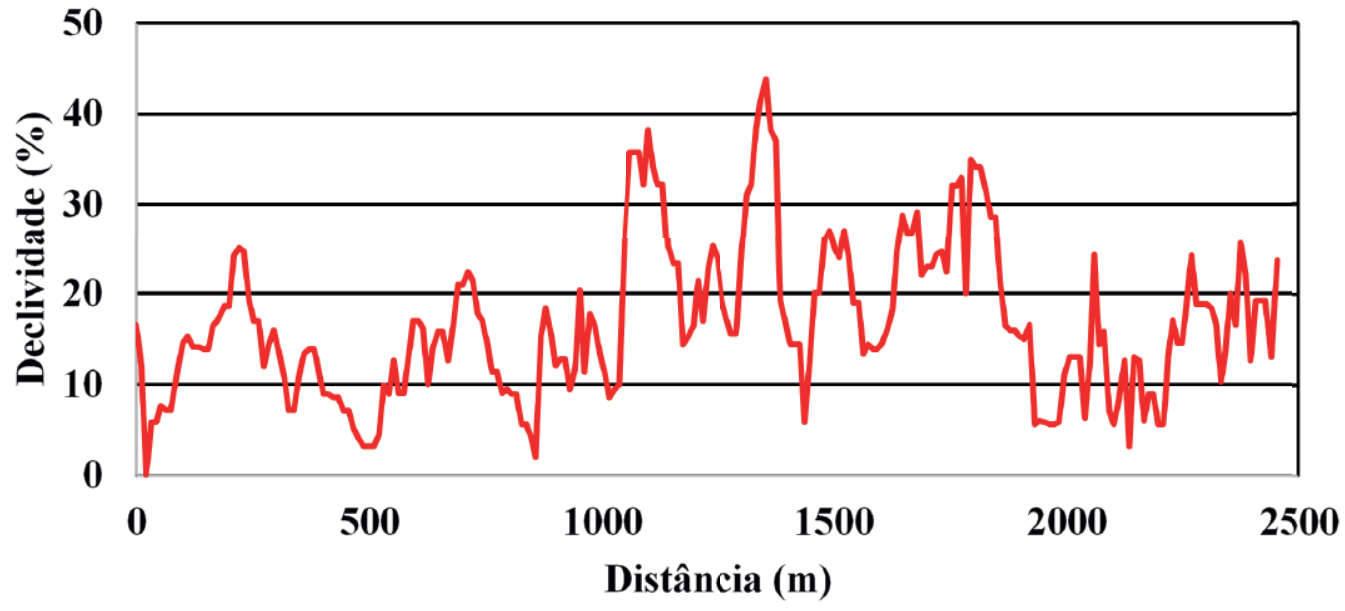

Figura 4. Hipsometria e declividade da Trilha das Flores. Fonte: Elaboração própria. 
$\mathrm{Na}$ Trilha da Barragem são encontrados os pontos Barragem e Casarão - o primeiro trata-se do reservatório hídrico Vaca Brava, que abastece Areia e municípios circunvizinhos e dá nome a trilha (figura 6A), enquanto o segundo é uma construção oriundas dos engenhos que estavam instalados na localidade antes da implantação da área protegida (figura 6B e 6C).

\section{(A) Hipsomteria - Trilha da Barragem}

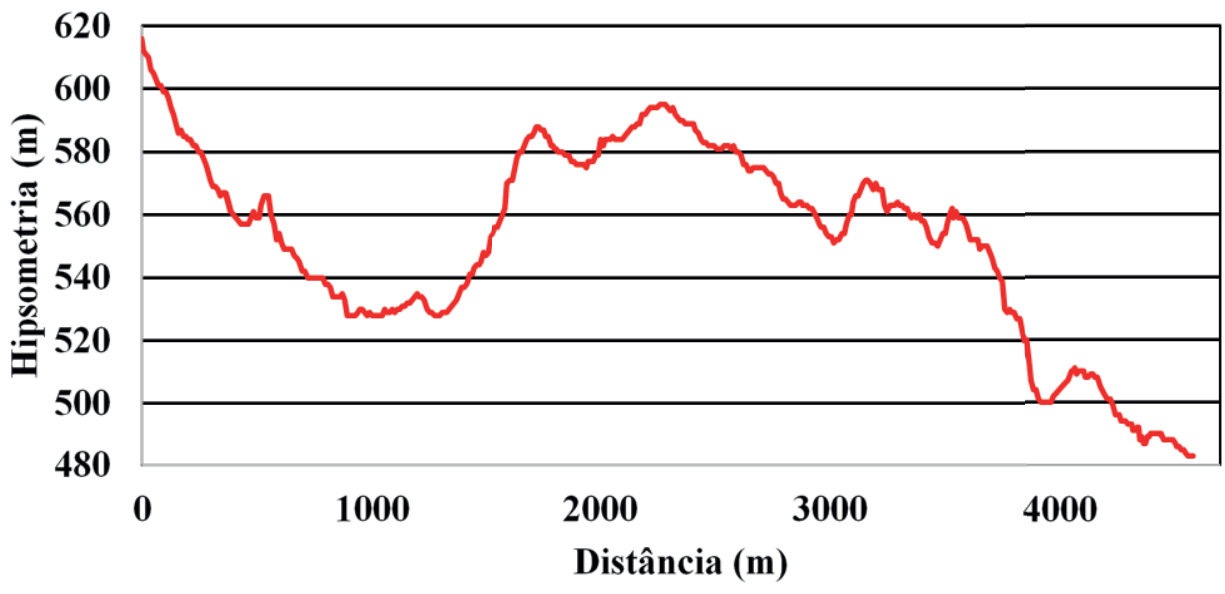

(B) Declividade - Trilha da Barragem

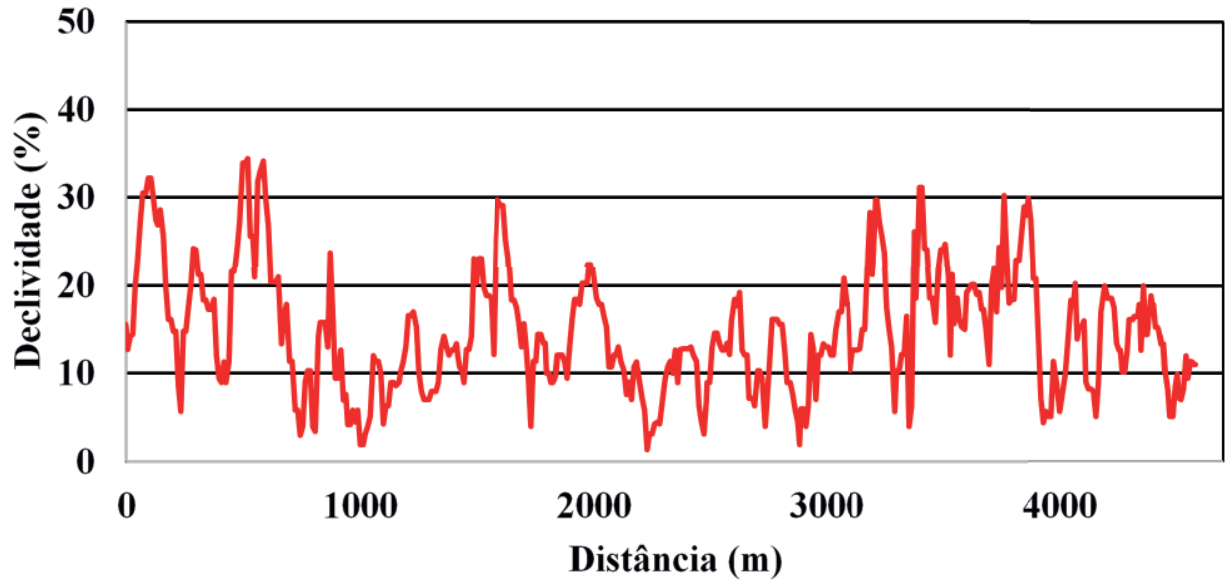

Figura 5. Hipsometria e declividade da Trilha da Barragem. Fonte: Elaboração própria.

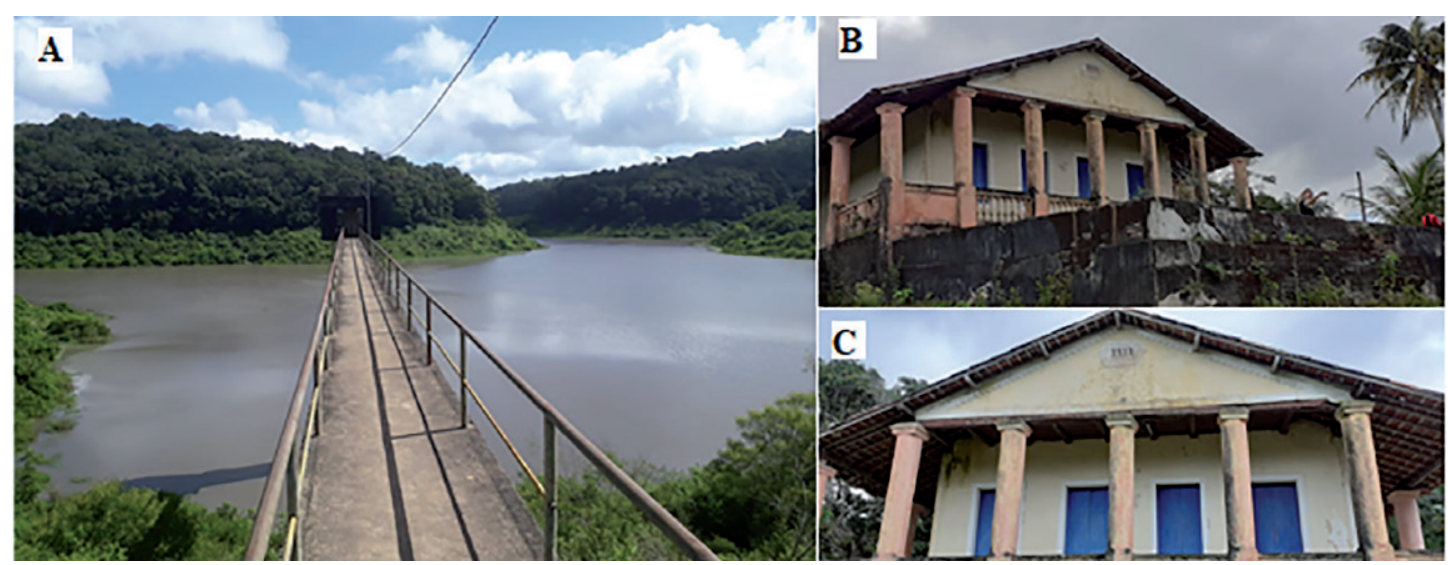

Figura 6. Atrativos turísticos encontrados na Trilha da Barragem: A - Barragem Vaca Brava; B e C - Casão. Fonte: Elaboração própria. 
Em relação às integrações, a Integração 1 situa-se na porção norte do Parque, próximo à Trilha Inicial, e possibilita a conexão entre as demais trilhas mapeadas. Assim como o trecho inicial da Trilha das Flores, é utilizada como parte da Trilha do Cumbe, o que permite estender o comprimento da trilha. Essa integração possui a menor extensão, à medida que a Integração 2, localizada na parte central do Parque, detém maior extensão.

A Integração 2, apesar de ser um percurso alternativo que permite estender a Trilha da Barragem, constitui o terceiro trajeto mais extenso do Parque. A porção onde está situada é pouco explorada do ponto de vista turístico, além disso, ao longo da sua extensão tem seu campo de visão limitado pelas árvores. Essa integração dá acesso ao atrativo da Cachoeira (figura 7), que se refere a uma queda d'água que se forma no rio Vaca Brava, situado na porção central do Parque, durante o período chuvoso, voltando a secar após esse período.

Mesmo sendo uma área protegida, o espaço da cachoeira é frequentemente acessado por moradores locais e visitantes sem guias para atividades de lazer, fato do qual se confirma pela presença de embalagens e resíduos orgânicos e inorgânicos encontrados. A presença de resíduos também foi constatada nas trilhas do Parque por Silva et al. (2006) e Pereira et al. (2019), o que demonstra ser uma ocorrência comum na unidade.

Em relação às classes de dificuldade apresentadas pelas trilhas, as mesmas foram obtidas por meio da sobreposição das variáveis ambientais no software ArcGIS. O mapa 03 mostra a espacialização das classes de dificuldade apresentadas por cada variável ambiental em acordo com as notas que lhe foram atribuídas. No mapa é possível verificar o produto final obtido a partir do somatório das variáveis, que, por sua vez, também se encontra reclassificado com as classes de dificuldade finais.

Com base no mapa 3, verifica-se que a declividade possui a maior variação das classes de dificuldade, uma vez que nela encontra-se representadas quatro das cinco classes adotadas. Por outro lado, as condições do terreno e a drenagem apresentam a menor variação de classes, apenas duas. Em seguida, a cobertura expõe três classes, com predominância de "muito fácil". A classe de dificuldade "moderado" se expressou em todas as variáveis ambientais, ao passo que a classe "muito difícil" está manifestada apenas na declividade.

Em razão de se manifestar apenas em uma das variáveis, a classe não é verificada no resultado do somatório, pois sua manifestação depende da soma de notas altas. Situação semelhante é atestada para a classe "muito fácil", a qual se encontra expressa somente na cobertura vegetal. No entanto, como depende das menores notas, a mesma está representada no produto final. O produto do somatório após convertido para o formato shapefile possibilitou recortar as trilhas em diferentes classes de dificuldade, conforme o mapa 4.

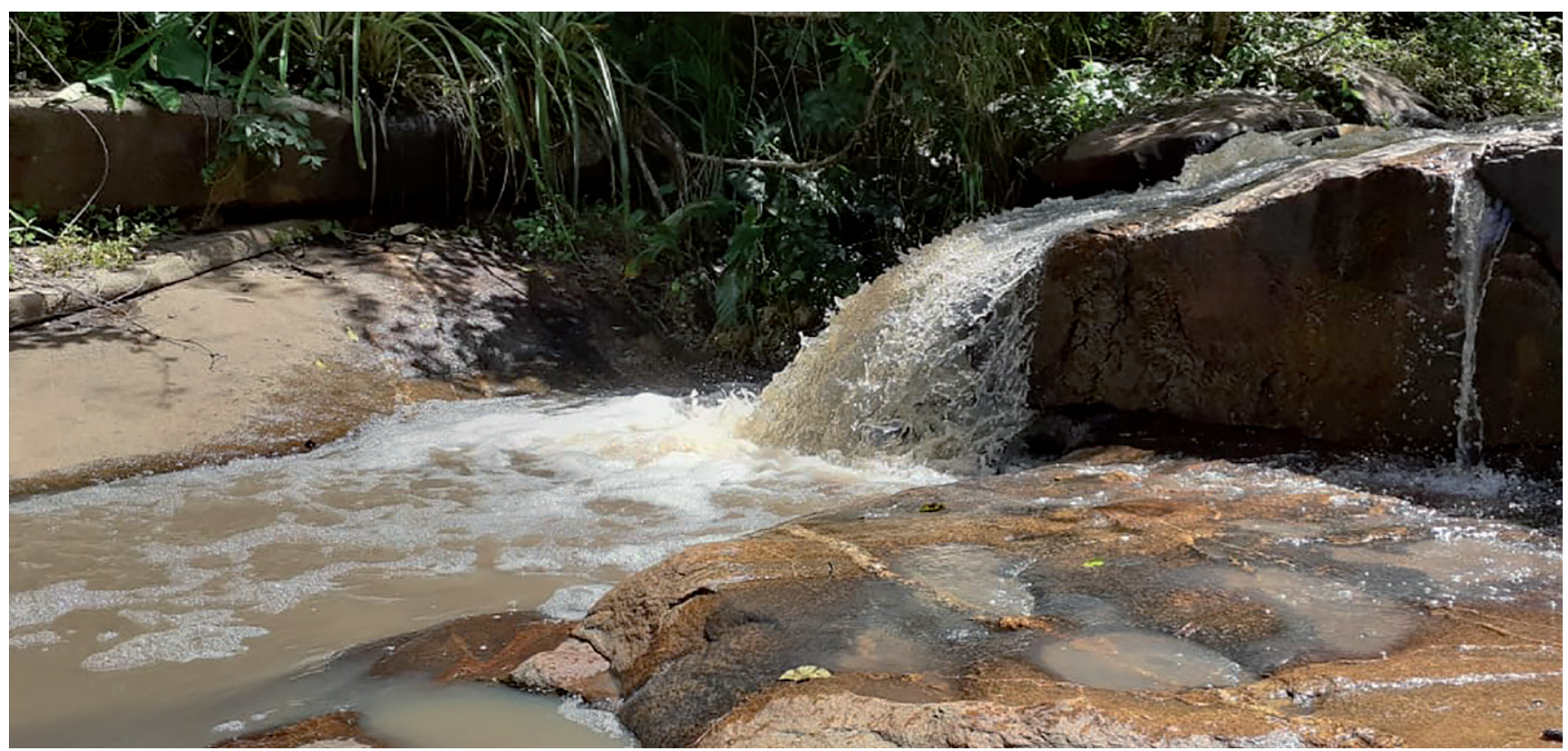

Figura 7. Cachoeira encontrada próximo da Integração 2 no período chuvoso. Fonte: Elaboração própria. 

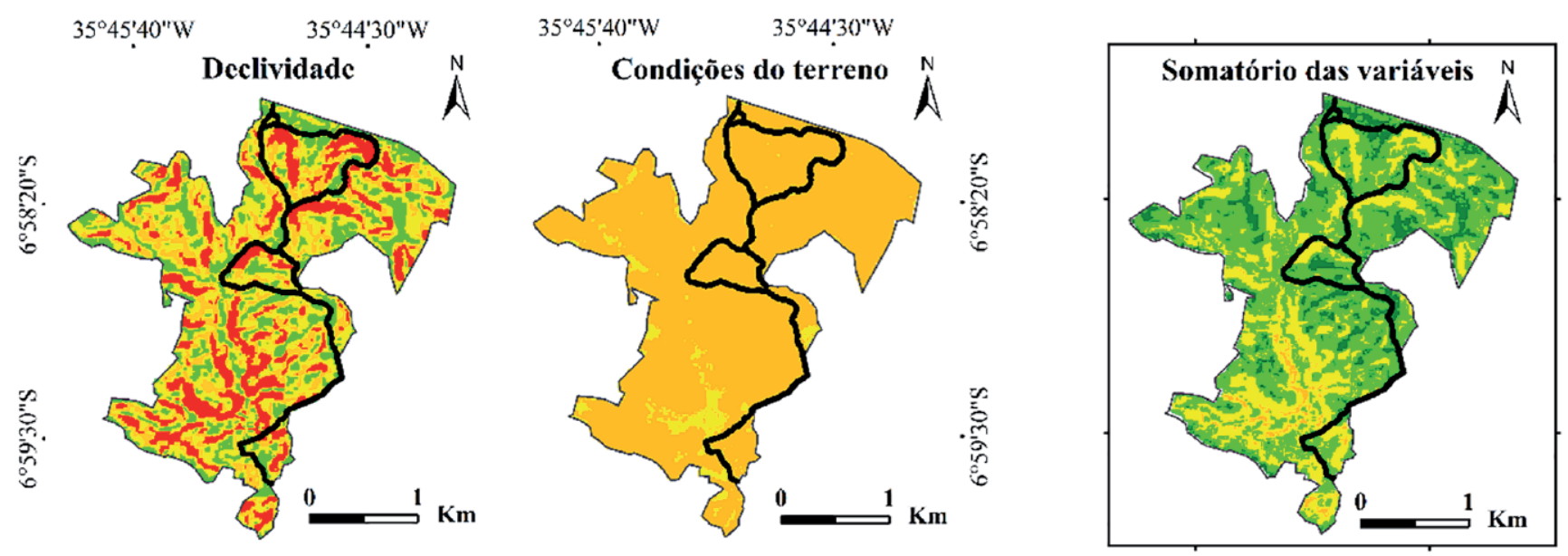

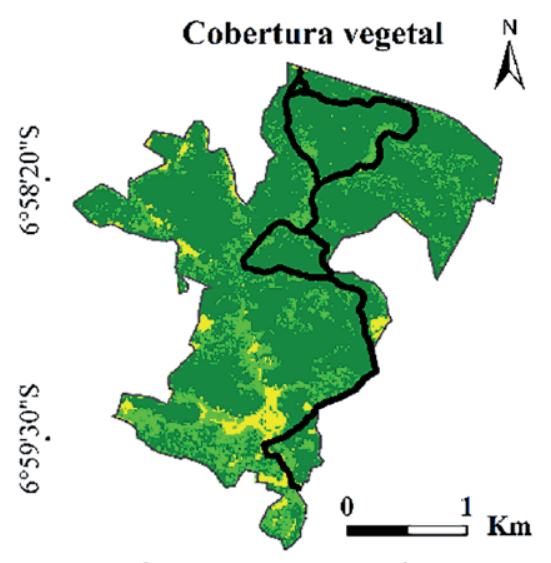

$35^{\circ} 45^{\circ} 40^{\prime \prime} \mathrm{W}$

$35^{\circ} 44^{1} 30^{\prime \prime} \mathrm{W}$

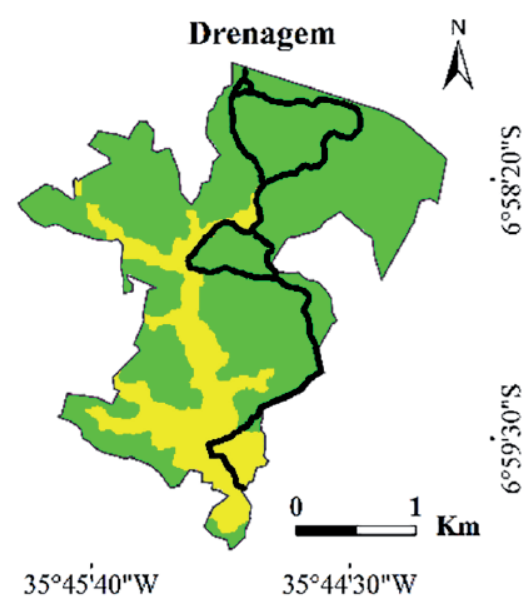

\begin{tabular}{|l|}
\hline Legenda \\
Classes de dificuldade \\
3 Muito difícil \\
3 Difícil \\
3 Moderado \\
$\checkmark$ Fácil \\
$\checkmark$ Trithas \\
3 PE Mata do Pau-Ferro \\
\hline
\end{tabular}

Sistema de Coordenadas Geográficas Datum: SIRGAS 2000

Fonte: SUDEMA (2020)

Composição: CAMPOS, J. O. (2021).

Mapa 3. Variáveis ambientais utilizadas na geração das classes de dificuldade das trilhas. Fonte: Elaboração própria.

A distância ocupada por cada classe de dificuldade nas trilhas, bem como o percentual de cada classe no sistema de trilhas é apresentado na tabela 3. A Trilha Inicial apresentada as classes "muito fácil" e "fácil", e ambas distam 0,003 e 0,049 km, respectivamente. As mesmas classes são observadas para a Trilha do Cumbe e a Integração 1, na primeira possuem distância de 0,056 e 0,112 km, enquanto na segunda possuem 0,047 e 0,098 km. Nos três percursos mencionados, ocorreu a predominância da classe "fácil".

Tabela 3. Distâncias ocupadas por cada classe de dificuldade nas trilhas do Parque.

\begin{tabular}{|l|c|c|c|c|c|c|c|c|}
\hline $\begin{array}{c}\text { Classes de } \\
\text { dificuldade }\end{array}$ & $\begin{array}{c}\text { Trilha } \\
\text { Inicial }\end{array}$ & $\begin{array}{c}\text { Trilha do } \\
\text { Cumbe }\end{array}$ & $\begin{array}{c}\text { Integração } \\
1\end{array}$ & $\begin{array}{c}\text { Integração } \\
2\end{array}$ & $\begin{array}{c}\text { Trilha das } \\
\text { Flores }\end{array}$ & $\begin{array}{c}\text { Trilha } \\
\text { da Barragem }\end{array}$ & Total (km) & \% \\
\hline Difícil & 0 & 0 & 0 & 0,012 & 0 & 0 & 0,012 & 0,13 \\
\hline Moderado & 0 & 0 & 0 & 0,518 & 0,259 & 0,655 & 1,431 & 15,96 \\
\hline Fácil & 0,049 & 0,112 & 0,098 & 0,879 & 1,629 & 3,278 & 6,046 & 67,41 \\
\hline Muito fácil & 0,003 & 0,056 & 0,074 & 0,135 & 0,564 & 0,647 & 1,479 & 16,49 \\
\hline Total (km) & $\mathbf{0 , 0 5 2}$ & $\mathbf{0 , 1 6 8}$ & $\mathbf{0 , 1 7 2}$ & $\mathbf{1 , 5 4 4}$ & $\mathbf{2 , 4 5 2}$ & $\mathbf{4 , 5 8 0}$ & $\mathbf{8 , 9 6 9}$ & $\mathbf{1 0 0 , 0 0}$ \\
\hline
\end{tabular}

Fonte: Elaboração própria. 


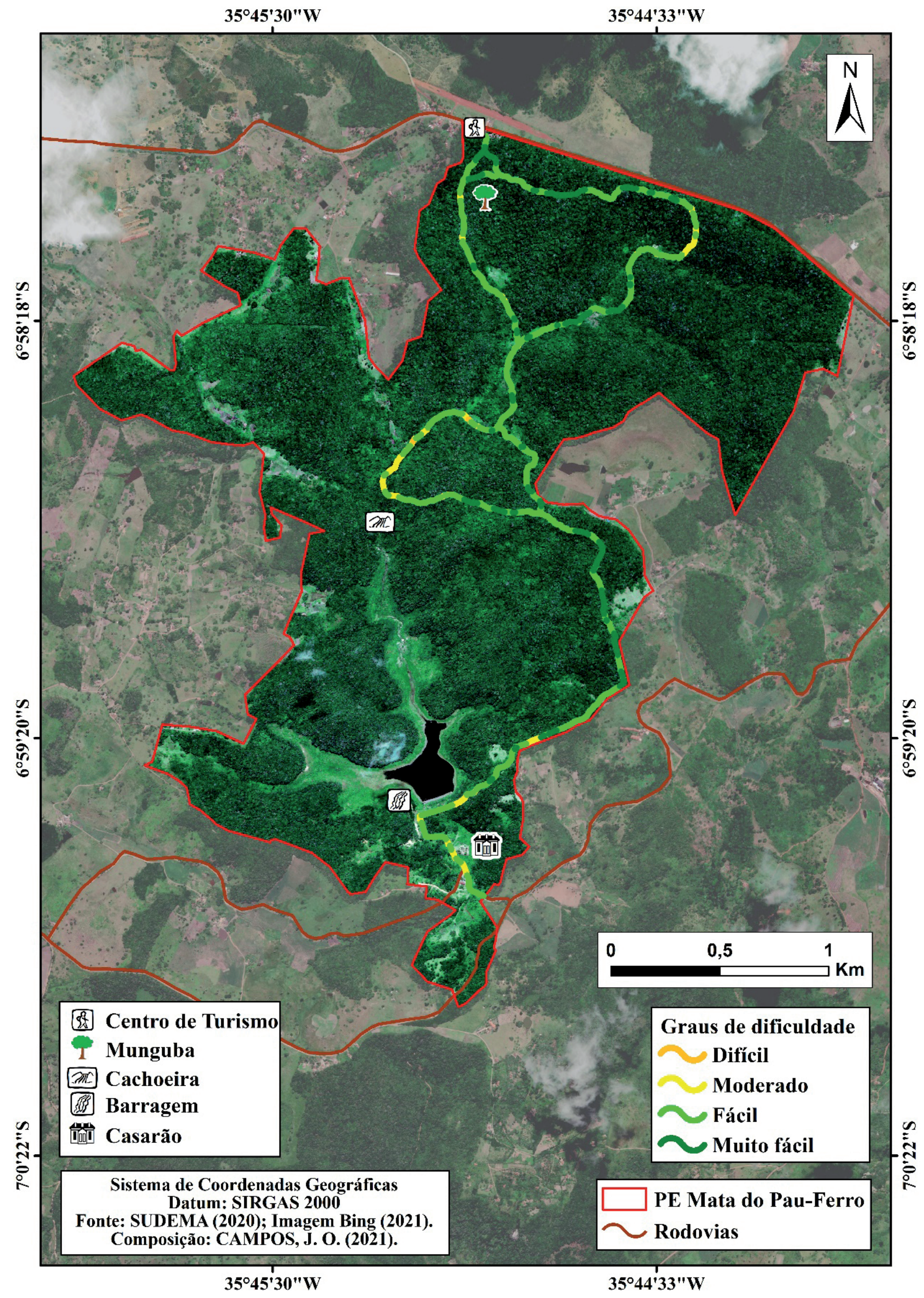

Mapa 4. Classes de dificuldade das trilhas do Parque. Fonte: Elaboração própria. 
$\mathrm{Na}$ Integração 2 são verificadas quatro classes de dificuldade, e, do mesmo modo que as trilhas anteriores, a maior parte da trilha é classificada como "fácil", compreendendo a distância de 0,879 km. Na Trilha das Flores a classe "difícil" está ausente, assim como na Trilha da Barragem, em que, seguindo a tendência verificada nas demais trilhas, a classe "fácil" abrange a maior quilometragem em ambas, somando 1,629 e $3,278 \mathrm{~km}$, na devida ordem.

A partir da análise da tabela 3, constata-se que o maior percentual das trilhas do Parque é classificado como "fácil", haja vista que a classe compreende $67,41 \%$ do sistema de trilhas. A classe "muito fácil" ocupa $16,49 \%$, e se manifesta de forma expressiva nas porções norte e sudeste. Os percursos classificados como moderado ocupam 15,96\% e ocorrem majoritariamente na parte central e sul da área. Por outro lado, os percursos classificados como "difícil" possuem a menor representatividade em termos de distância, ocupando apenas $0,13 \%$ do sistema, tendo sua ocorrência restrita à porção central, onde se localiza a Integração 2 .

Percentuais divergentes foram encontrados por Silva e Palhares (2020), no Parque Estadual Serra do Cabral, em Minas Gerais, onde os autores verificaram que a classe "difícil" é a mais representativa da Trilha do Mirante, abrangendo $45 \%$ da mesma, ao passo que as classes "moderado", "fácil" e "muito fácil", ocupam $35 \%, 18 \%$ e $3 \%$, respectivamente.

Silva (2016) mapeando trilhas no Parque Nacional do Itatiaia, verficou que a Trilha das Prateleiras possui predominância da classe "muito difícil", na qual constitui $45,4 \%$ de sua extensão, enquanto na Trilha das Agulhas Negras a classe "fácil" é a mais representativa, com um percentual de $46,9 \%$, sendo o resultado que mais se aproxima dos percentuais verficados no presente estudo. A maior ocorrência das classes "muito fácil" e "fácil" nas trilhas demonstra que as mesmas podem receber um público diverso de visitantes, desde iniciantes até os mais experientes. Tal realidade é de suma importância, pois permite que novos visitantes sejam atraídos, aumentando o público divulgador dos atributos naturais e beleza cênica da paisagem.

A predominância da classe de dificuldade fácil também releva a não exigência de condicionamento físico para o tráfego. No entanto, como a classe se encontra distribuída em fragmentos no sistema de triIhas, há que observar se as classes de dificuldade que se apresentam no intermeio delas não constituem obstáculos aos visitantes. Reforça-se a recomendação, quando tratar-se da porção central do Parque, onde ocorre a classe difícil, embora em menor percentual. Ao mesmo tempo, se faz importante anunciar que, durante eventos de chuva ou período chuvoso na região, os graus de dificuldade das trilhas constatados podem não condizer com a realidade em decorrência de dinâmicas condicionadas pelas variáveis ambientais, tais como: aumento da calha dos rios de cortam o Parque, risco de queda de árvores, exposição à chuva e maior risco de acidente devido ao solo escorregadio, principalmente em trechos de maior declividade.

O mapeamento das trilhas em conjunto com os atributos morfométricos do terreno e a classificação da dificuldade, aqui apresentados, podem ser utilizados para planejar a capacidade de suporte e as atividades que podem ser desenvolvidas ao longo das trilhas, pois é possível observar como as trilhas se distribuem na unidade e os gradientes de altitude e declividade que experimentam - aspectos estes que influenciam na distribuição dos seres vivos e na erosão dos solos. Além disso, a espacialização das classes de dificuldade possibilita aos visitantes maiores informações sobre as trilhas, o que oportuniza a escolha da trilha mais adequada aos seus interesses.

No mapeamento foram desconsideradas as trilhas que não são mantidas pelos guias, pois são trilhas não controladas que ocorrem em toda a unidade, abertas por moradores locais para fins turísticos, conflito que se pronuncia em virtude da baixa fiscalização nos limites da área, decorrente da baixa disponibilidade de recursos para gestão. Diante disso, a divulgação das informações geradas sobre o sistema de trilhas pode auxiliar na formalização da atividade de visitação no Parque, possibilitando que os visitantes priorizarem as trilhadas mapeadas ao invés de trilhas alternativas, sem trajeto conhecido.

A priorização das trilhas mapeadas ao invés de trilhas não controladas, por parte dos visitantes, pode contribuir para a redução da abertura de novos percursos, em razão da menor procura. Desse modo, serão evitados maiores impactos sobre os ecossistemas (Decanini, 2001; Boquimpani-Freitas et al., 2020). Além disso, as trilhas não controladas poderão ser desativadas, em virtude do desuso e experimentar a regeneração da vegetação afetada. 
A formalização de um sistema de trilhas é de fundamental importância, não só do ponto de vista turístico, mas também no que se refere às perturbações ecológicas, pois a manutenção e criação de novos trajetos pode ocasionar e intensificar a propagação dos efeitos de borda para áreas interioranas dos fragmentos florestais, levando à redução na qualidade ambiental (Figueiró \& Coelho Netto, 2009; Mitchell et al., 2015; Campos et al., 2018).

Dito isso, a exibição dos mapas de trilhas no Centro de Turismo e em mídias digitais locais, juntamente com a disponibilidade dos guias, poderá decisivamente encaminhar a atividade de visitação no Parque para caminhos voltados à conservação e ao desenvolvimento social, econômico e cultural. Apesar do conhecimento das perturbações causadas por trilhas em Unidades de Conservação (Rangel et al., 2013; Costa et al., 2019), oportunizar as comunidades locais a desenvolverem atividades turísticas associadas às mesmas, surge como uma das formas mais efetivas para resolução dos conflitos que se manifestam, além de fortalecer o intercâmbio entre órgão gestor e sociedade civil.

\section{CONCLUSÕES}

O Parque Estadual Mata do Pau-Ferro possui um sistema composto por 4 trilhas, 2 integrações e quatro pontos na paisagem que funcionam como atrativos turísticos principais, em que maior parte dos percursos são classificados como fácil, isto é, não demandam maiores esforços físicos para sua realização. Além disso, o Parque encontra-se circundado por moradores que desenvolvem atividades econômicas sustentáveis associadas a Unidade de Conservação, a exemplo do ecoturismo, com possibilidade de expansão para maior número de pessoas.

Essa conjuntura reforça o potencial turístico da Unidade da Conservação para receber diversos grupos de visitantes simultaneamente, e se consolidar como um dos espaços mais apropriados para realização de visitação e trilha interpretativa no estado da Paraíba, além de contribuir para a renda dos moradores locais. Tais aspectos são reforçados por se tratar de um dos maiores remanescentes de Mata Atlântica do estado em Brejo de Altitude, e abrigar espécies ameaçadas de extinção. Nesse caminho, a divulgação da importância da área, o aumento no número de visitantes e implantação de estruturas adequadas à manutenção da visitação podem suscitar recursos financeiros e novas perspectivas para proteção da área em questão.

Do ponto de vista da gestão, as informações geradas podem ser utilizadas para planejamento da capacidade de suporte das trilhas, bem como da suscetibilidade das mesmas à erosão, com vistas a proporcionar uma melhor experiência aos visitantes e, ao mesmo tempo, minimizar os impactos da atividade sobre os ecossistemas. A visitação, além de estar voltada aos objetivos propostos para a categoria Parque, permite a conscientização ambiental através do contato com os ecossistemas, evidenciando a necessidade do trabalho conjunto entre sociedade civil e órgão gestor para uma efetiva gestão da área protegida.

\section{Declaração responsável e conflito de interesses}

Os autores declaram não haver conflito de interesse em relação à publicação deste artigo. Os dois autores contribuíram igualmente nos seguintes pontos: revisão bibliográfica, desenho metodológico, trabalho de campo e redação do artigo.

\section{REFERÊNCIAS}

Ab'Sáber, A. N. (2003). Os domínios de natureza no Brasil: potencialidades paisagísticas. Ateliê Editorial.

Aguiar, P. C. B., Moreau, A. M. S. S. \& Fontes, E. O. (2013). Áreas Naturais Protegidas: Um Breve Histórico Do Surgimento Dos Parques Nacionais E Das Reservas Extrativistas. Revista Geográfica de América Central, 1(50), 195-213. https:// www.redalyc.org/articulo.oa?id $=451744541007$ 
Andrade, G. O. \& Lins, R. C. (1964). Introdução ao estudo dos "Brejos"Pernambucanos. Arquivos do Instituto de Ciências da Terra da Universidade de Recife, 2, 21-34.

Beltrão, B. A., Morais, F., Mascarenhas, J. C., Miranda, J. L. F., Junior, L. C. S. \& Mendes, V. A. (Orgs.). (2005). Projeto cadastro de fontes de abastecimento por água subterrânea estado de Paraíba: diagnóstico do município de Areia. CPRM/PRODEEM.

Bétard, F., Peulvast, J.-P. \& Sales, V. C. (2007). Caracterização morfopedólogica de uma serra úmida no semi-árido do Nordeste brasileiro: o caso do maciço de Baturité-CE. Mercator - Revista de Geografia da UFC, 6(12), 107-126. http:// www.mercator.ufc.br/mercator/article/view/49

Boquimpani-Freitas, L., Costa, N. M. C. da \& Pereira, R. A. (2020). Caracterização e análise da declividade das trilhas do Parque Nacional da Tijuca: subsídios para a gestão da visitação. Geosul, 35(75), 556-579. https://doi.org/10.5007/1 982-5153.2020v35n75p556

Brasil (2007). Informe nacional sobre áreas protegidas no Brasil. MMA.

Brasil (2011). SNUC: Lei $n^{\circ}$ 9.985, de 18 de julho de 2000; Decreto $n^{\circ}$ 4.340, de 22 de agosto de 2002; Decreto $n^{\circ} 5.746$, de 5 de abril de 2006. Plano Estratégico Nacional de Áreas Protegidas: Decreto n 5.758, de 13 de abril de 2006. MMA.

Brasil (2020). Cadastro Nacional de Unidades de Conservação: Unidades de Conservação por Bioma. MMA.

Campos, J. O. \& Lima, V. R. P. (2020). Proposta de Zoneamento Ambiental para o Parque Estadual Mata do Pau Ferro, Paraíba, Brasil. Physis Terrae - Revista Ibero-Afro-Americana de Geografia Física e Ambiente, 2(1), 19-46. https://doi. org/10.21814/physisterrae.2425

Campos, J. O., Santos, J. S., Salvador, M. S. S. \& Lima, V. R. P. (2018). Análise e propagação dos efeitos de borda no Parque Estadual Mata do Pau-Ferro, Areia-PB. Revista Geográfica Acadêmica, 12(2), 21-36. https://revista.ufrr.br/rga/article/ view/5103

Canto-Silva, C. R. \& Silva, J. S. (2017). Panorama da visitação e da condução de visitantes em Parques brasileiros. Revista Brasileira de Pesquisa em Turismo, 11(2), 365-386. https://doi.org/10.7784/rbtur.v11i2.1286

Castro Júnior, E., Coutinho, B. H. \& Freitas, L. E. (2009). Gestão da biodiversidade e áreas protegidas. In A. J. T. Guerra \& M. C. N. Coelho (Orgs.), Unidades de Conservação: abordagens e características geográficas (p. 25-65). Bertrand Brasil.

Costa, P. G., Pimentel, D. de S., Simon, A. V. S. \& Correia, A. R. (2019). Trilhas Interpretativas para o Uso Público em Parques: desafios para a Educação Ambiental. Revista Brasileira de Ecoturismo (RBEcotur), 12(5), 818-839. https://doi. org/10.34024/rbecotur.2019.v12.6769

Decanini, M. M. (2001). SIG no Planejamento de trilhas no Parque Estadual de Campos do Jordão. Revista Brasileira de Cartografia, 53, 97-110. http://www.rbc.Isie.unb.br/index.php/rbc/article/download/202/185

Decreto n²6.098, de 04 de agosto de 2005, Diário Oficial [do] Estado da Paraíba 2 (2005). https://www.jusbrasil.com.br/ diarios/44314636/doepb-05-08-2005-pg-2?ref=next_button

Diaz del Olmo, F. \& Molina Vezquez, F. (1985). Parques naturales andaluces: una estrategia de conservacion y desarrollo en regiones deprimidas. Revista de Estudios Andaluces, (4), 147 - 156. https://doi.org/10.12795/rea.1985.i04.08

Diegues, A. C. (2008). O mito moderno da natureza intocada (6 ed). Hucitec: Nupaub - USP/CEC.

Dorst, J. (1973). Antes que a natureza morra: por uma ecologia política (R. Buongermino (trad.)). Edgard Blucher.

Drummond, J. A., Franco, J. L. A. \& Oliveira, D. (2010). Uma análise sobre a história e a situação das unidades de conservação no Brasil. In R. S. Ganem (Org.), Conservação da Biodiversidade Legislação e Políticas Públicas (p. 341-386). Câmara dos Deputados, Edições Câmara.

Figueiró, A. S. \& Coelho Netto, A. L. (2009). Impacto ambiental ao longo de trilhas em áreas de floresta tropical de encosta: Maciço da Tijuca Rio de Janeiro - RJ. Mercator, 8(16), 187-200. https://doi.org/10.4215/RM2009.0816.0015

Ganem, R. S. \& Drummond, J. A. (2010). Biologia da conservação: as bases científicas da proteção da biodiversidade. In Roseli Senna Ganem (Org.), Conservação da Biodiversidade Legislação e Políticas Públicas (p. 11-46). Câmara dos Deputados, Edições Câmara.

Godoy, L. C. R. C. \& Leuzinger, M. D. (2015). O financiamento do Sistema Nacional de Unidades de Conservação no Brasil: Características e tendências. Revista de Informação Legis/ativa - RIL, 52(206), 223-243. https://www12.senado.leg.br/ ril/edicoes/52/206/ril_v52_n206_p223.pdf

Gomes, P. O. \& Cunha, A. A. (2018). A importância da visitação nos parques nacionais e a geração de recursos financeiros. Revista Cenário, 6(10), 112-125. https://doi.org/10.26512/revistacenario.v6i10.18899

Ibama (2002). Roteiro metodológico de planejamento: Parque Nacional, Reserva Biológica, Estação Ecológica. IBAMA. 
Juras, I. da A. G. M. (2010). Instrumentos para a conservação da biodiversidade. In R. S. Ganem (Org.), Conservação da Biodiversidade Legislação e Políticas Públicas (p. 223-284). Câmara dos Deputados, Edições Câmara.

Marion, J. L. \& Wimpey, J. (2017). Assessing the influence of sustainable trail design and maintenance on soil loss. Journal of Environmental Management, 189, 46-57. https://doi.org/10.1016/j.jenvman.2016.11.074

Marques, A. D. L., Costa, C. R. G. \& Moura, D. C. (2019). Parque Estadual Mata do Pau Ferro (Areia - Paraíba): Zona de Amortecimento e espaços de conflitos. Geoambiente On-line, 34, 1-18. https://doi.org/10.5216/revgeoamb.v0i34.52282

Medeiros, J. F. \& Cestaro, L. A. (2019). As diferentes abordagens utilizadas para definir brejos de altitude, áreas de exceção do Nordeste brasileiro. Sociedade e Território, 31(2), 97-119. https://doi.org/10.21680/2177-8396.2019v31n2ID16096

Medeiros, R. (2006). Evolução das tipologias e categorias de áreas protegidas no Brasil. Ambiente \& Sociedade, 9(1), 41-64. https://doi.org/10.1590/S1414-753X2006000100003

Medeiros, R., Young, C. E. F., Pavese, H., Araújo, F. F. S., Pereira, G. S., Rodrigues, C. G. O., Valverde, Y., Pinto, E. M., Stein, B., Gurgel, H. C., Santos, F. R. P. dos \& Neves, L. H. (2011). Unidades de conservação e desenvolvimento: a contribuição do SNUC para economia nacional. In R. Medeiros \& F. F. S. Araújo (Orgs.), Dez anos do Sistema Nacional de Unidades de Conservação da Natureza: lições do passado, realizações presentes e perspectivas para o futuro (p. 55-88). MMA.

Mitchell, M. G. E., Suarez-Castro, A. F., Martinez-Harms, M., Maron, M., McAlpine, C., Gaston, K. J., Johansen, K. \& Rhodes, J. R. (2015). Reframing landscape fragmentation's effects on ecosystem services. Trends in Ecology \& Evolution, 30(4), 190-198. https://doi.org/10.1016/j.tree.2015.01.011

Morsello, C. (2001). Áreas protegidas públicas e privadas: seleção e manejo. Annablume.

Myers, N., Mittermeier, R. A., Mittermeier, C. G., da Fonseca, G. A. B. \& Kent, J. (2000). Biodiversity hotspots for conservation priorities. Nature, 403(6772), 853-858. https://doi.org/10.1038/35002501

Paraíba. (1985). Atlas geográfico do Estado da Paraíba. Grafset.

Pereira, T. F., Campos, J. O., Pereira, M. R. S. \& Lima, V. R. P. (2019). Ecoturismo e os impactos ambientais no Parque Estadual Mata do Pau-ferro, Areia, Paraíba. Revista Geotemas, 9(1), 128-143. https://doi.org/10.33237/geotemas. v9i1.3382

Pennington, R. T., Lavin, M., Prado, D. E., Pendry, C. A., Pell, S. K. \& Butterworth, C. A. (2004). Historical climate change and speciation: neotropical seasonally dry forest plants show patterns of both Tertiary and Quaternary diversification. Philosophical Transactions of the Royal Society of London. Series B: Biological Sciences, 359(1443), 515-538. https://doi. org/10.1098/rstb.2003.1435

Primack, R. B. \& Rodrigues, E. (2001). Biologia da conservação. E. Rodrigues.

Pureza, F., Pellin, A. \& Padua, C. (2015). Unidades de Conservação: fatores e personagens que fizeram a história das categorias de manejo. Matrix.

Rangel, L. de A., Guerra, T. J. A., Brizzi, R. R. \& Souza, H. S. (2013). O uso de trilhas em unidades de conservação: o caso da Apa de Cairuçu, Paraty - RJ. Geografia, 22(1), 79-93. https://doi.org/10.5433/2447-1747.2013v22n1p79

Rezende, V. L. \& Cunha, F. L. (2014). OS DESAFIOS DO USO DE TRILHAS EM UNIDADES DE CONSERVAÇÃO. Periódico Eletrônico Fórum Ambiental da Alta Paulista, 10(3), 29-41. https://doi.org/10.17271/198008271032014839

Robim, M. D. J. \& Tabanez, M. F. (1993). Subsídios para implantação da Trilha Interpretativa da Cachoeira - Parque Estadual de Campos do Jordão. Revista Instituto Florestal, 5(1), 65-89.

Santos, H. A., Costa, E. G., Araújo, H. F., Mendonça, J. D. L. \& Silva, T. C. F. (2020). Plano de manejo do Parque Estadual Mata do Pau-Ferro. Editora UNIESP.

Santos, S. S., Pedrosa, K. M., Andrade, E. S., Silva, J. S., Rodrigues, E. F. \& Xavier, W. J. F. (2020). Trilhas interpretativas utilizadas como recurso pedagógico: formação e informação no ensino básico. Revista Brasileira de Gestão Ambiental e Sustentabilidade, 7(16), 749-769. https://doi.org/10.21438/rbgas(2020)071621

SFB. (2019). Inventário Florestal Nacional: principais resultados: Paraíba. MAPA.

Silva, G. G. L. (2016). Classificação do grau de dificuldade de trilhas : uso de geotecnologias na elaboração de um modelo aplicado ao Parque Nacional do Itatiaia, Brasil [Dissertação (Mestrado em Ciências)]. Programa de Pós-Graduação em Turismo, Escola de Artes, Ciências e Humanidades, Universidade de São Paulo - USP.

Silva, G. G. L., Lima, T. C. \& Panchaud, L. (2016). Mapeamento e Classificação do Grau de Dificuldade da Trilha do Rancho Caído, Parque Nacional do Itatiaia (RJ). Revista Brasileira de Ecoturismo (RBEcotur), 9(2), 250-272. https://doi. org/10.34024/rbecotur.2016.v9.6443 
Silva, M. C., Queiroz, J. E. R., Araujo, K. D. \& Pazera Jr, E. (2006). Condições ambientais da Reserva Ecológica Estadual da Mata do Pau-Ferro, Areia - PB. Geografia, 15(1), 51-63. http://www.uel.br/revistas/uel//index.php/geografia/article/ view/6644/6001

Silva, T. N. \& Palhares, R. H. (2020). Parque Estadual Serra do Cabral em Minas Gerais: classificação do grau de dificuldade da trilha do mirante. Revista Cerrados, 18(02), 512-535. https://doi.org/10.46551/rc24482692202027

Simões, L. L. (2008). Unidades de conservação: conservando a vida, os bens e os serviços ambientais. WWF - Brasil.

Souza, J. L., Vieira, C. L. \& Silva, D. C. B. (2015). Roteiro metodológico para elaboração de plano de manejo para Reservas Particulares do Patrimônio Natural. Brasília - DF: Instituto Chico Mendes de Conservação da Biodiversidade, 2015. 86p. Instituto Chico Mendes de Conservação da Biodiversidade.

Tabarelli, M. \& Santos, A. M. M. (2004). Uma breve descrição sobre a história natural dos Brejos Nordestinos. In K. C. PORTO, J. J. P. CABRAL, \& M. TABARELLI (Orgs.), Brejos de altitude em Pernambuco e Paraíba: história natural, ecologia e conservação (p. 17-24). MMA.

Veloso, H. P., Rangel Filho, A. L. R. \& LIMA, J. C. A. (1991). Classificação da vegetação brasileira, adaptada a um sistema universal. IBGE. 